\title{
Grupo de Monitoramento do Linfedema: Cuidados Pós- Alta de um Programa de Reabilitação nos Pacientes com Câncer de Mama
}

Tavares, Aline Cristina; Velar, Camila Molina; Bueno, Camila da Silva; Bazan, Mellik; Brito, Christina May Moran de; Toscano, Juliana Lopes

Icesp — aline.tavares@icesp.org.br

INTRODUÇÃO: o câncer (CA) de mama é a neoplasia mais comum entre mulheres, no mundo e no Brasil.. Durante o tratamento ou pela própria doença, complicações físicas podem surgir, tais como: limitação e diminuição de movimentos de ombro e braço, diminuição de força muscular, dor, fibrose da articulação escapuloumeral e linfedema (15 a 20\% dos casos). Após a alta do programa de reabilitação, a falta de aderência às orientações ou em casos de necessidade de reintervenção cirúrgica e/ou de radioterapia, essas complicações podem reaparecer ou se agravar. a formação de grupos de orientação propicia benefícios aos participantes pelo acolhimento, manutenção do cuidado e identificação de possíveis complicações no período pós- alta. OBJETIVOS: Reforçar cuidados e orientações, avaliar instalação/progressão do linfedema após a alta de um programa de reabilitação e decidir se a paciente necessitará retornar para um atendimento individualizado. MÉTODOS: Trata-se de um estudo observacional em andamento, com pacientes que receberam alta do programa supervisionado de reabilitação, com o diagnóstico de câncer de mama e linfedema (grau 0 ou latente, grau 1 reversível espontaneamente, grau 2 irreversível espontaneamente e grau 3 irreversível com fibrose e/ou outras complicações). Os grupos de orientação constituem 2 encontros no segundo e no terceiro mês após alta do programa de reabilitação com a participação da fisioterapia, da terapia ocupacional e do psicólogo. Durante os encontros as pacientes são (i) reorientadas quanto às adequações em suas atividades cotidianas e a necessidade de adaptações em suas funções; (ii) avaliadas se o linfedema está estável ou não; (iii) caso o linfedema não esteja estável, é discutida com o fisiatra a necessidade de reenquadramento em programa de reabilitação. As perdas foram consideradas como não participações nos encontros em decorrência de faltas, seja por intercorrência clínica, óbito ou recusa. RESULTADOS: Os resultados parciais incluem 67 pacientes. dos 32 pacientes que apresentavam linfedema subclínico, houve $7(22 \%)$ perdas, 23 (72\%) mantiveram o linfedema estável, e 2 (6\%) apresentaram piora e foram reenquadrados no programa. dos 13 pacientes que apresentavam linfedema grau 1, houve 2 (15\%) perdas, 11 (85\%) mantiveram o linfedema estável, e nenhum apresentou piora do quadro. dos 17 pacientes que apresentavam linfedema grau 2, houve 1 (6\%) perda, 13 (76\%) mantiveram o linfedema estável, e $3(18 \%)$ apresentaram piora e foram reenquadrados no programa. dos 5 pacientes que apresentavam linfedema grau 3, 1 (20\%) manteve o linfedema estável, e 4 (80\%) apresentaram piora e foram reenquadrados no programa. CONCLUSÃO: o grupo de orientação pós-alta contribui para a promoção da estabilidade do linfedema, assim como para o reconhecimento de complicações e necessidade de novas intervenções de reabilitação nessa população.

Tavares, Aline Cristina; Velar, Camila Molina; Bueno, Camila da Silva; Bazan, Mellik; Brito, Christina May Moran de; Toscano, Juliana Lopes. Grupo de Monitoramento do Linfedema: Cuidados Pós- Alta de um Programa de Reabilitação nos Pacientes com Câncer de Mama. In: Anais do Congresso Internacional de Humanidades \& Humanização em Saúde [= Blucher Medical Proceedings, num.2, vol.1]. São Paulo: Editora Blucher, 2014. ISSN 2357-7282

DOI 10.5151/medpro-cihhs-10703 